\title{
Non-contiguous finished genome sequence and description of Anaerococcus pacaensis sp. nov., a new species of anaerobic bacterium Isabelle Pagnier ${ }^{1}$, Olivier Croce ${ }^{1}$, Catherine Robert ${ }^{1}$ Didier Raoult ${ }^{1}$ and Bernard La Scola ${ }^{1 *}$ \\ ${ }^{1}$ Unité de Recherche sur les Maladies Infectieuses et Tropicales Emergentes Faculté de médecine, Aix-Marseille Université, Marseille, France \\ *Correspondence: Bernard La Scola (bernard.la-scola@univ-amu.fr) \\ Keywords: Anaerococcus pacaensis, genome
}

Anaerococcus pacaensis strain $9403502^{\top}$, is the type strain of Anaerococcus pacaensis sp. nov., a new species within a new genus Anaerococcus. This strain, whose genome is described here, was isolated from a blood sample. A. pacaensis strain $9403502^{\top}$ is an obligate anaerobic Grampositive coccus. Here we describe the features of this organism, together with the complete genome sequence and annotation. The $2.36 \mathrm{Mbp}$ long genome exhibits a $\mathrm{G}+\mathrm{C}$ content of $35.05 \%$ and contains 2,186 protein-coding and 72 RNA genes, including 3 rRNA genes.

\section{Introduction}

Anaerococcus pacaensis strain $9403502^{\mathrm{T}}$ (= CSUR $\mathrm{P} 122=$ DSM 26346), is the type strain of Anaerococcus pacaensis sp. nov., and a member of the genus Anaerococcus. This bacterium is a Grampositive, anaerobic, non spore-forming, indole negative coccus that was isolated from a blood sample, during a study prospecting anaerobic isolates from deep samples [1].

The "gold standard" method to define a new bacterial species or genus is DNA-DNA hybridization and $\mathrm{G}+\mathrm{C}$ content determination [2]. Those methods are expensive and poorly reproducible and actually, bacterial species can be classified with PCR and sequencing methods, particularly $16 \mathrm{~S}$ rRNA sequences with internationally-validated cutoff [3]. More recently, an increasing number new bacterial genera and species have been described using high throughput genome sequencing and mass spectrometric analyses that allow access to the wealth of genetic and proteomic information [4,5]. In the past, studies have described new bacterial species and genera using genome sequencing, MALDI-TOF spectra, main phenotypic characteristics [6-23], and we propose here to describe a new species within the genus Anaerococcus in the same way.

Here we present a summary classification and a set of features for A. pacaensis sp. nov. strain $9403502^{\mathrm{T}}$ (= CSUR P122= DSM 26346) together with the description of the complete genomic sequencing and annotation. These characteristics support the circumscription of a novel species, Anaerococcus pacaensis sp. nov., within the genus Anaerococcus, and within the Clostridiales Family XI Incertae sedis.
The genus Anaerococcus was first described in 2001 [24], and belongs to the Clostridiales Family $\mathrm{XI}$ Incertae sedis. This family is defined mainly on the basis of phylogenetic analyses of ARNr $16 \mathrm{~S}$ sequences, and in the Anaerococcus genus, bacteria are all anaerobic gram positive cocci. Based on the comparison of the 16S rRNA gene sequence, the first closest related species to Anaerococcus pacaensis sp., nov., is Anaerococcus prevotii. It was first described in 1948 by Foubert and Douglas [25] and reclassified later in the genus Anaerococcus [24]. The second closest related species is $A$. octavius, which was described first as Peptostreptococcus octavius, isolated from a human sample in 1998 by Murdoch et al [26]. It was later re-classified in the genus Anaerococcus, as $A$. octavius [24].

\section{Classification and features}

A blood sample was collected from a patient during a study analyzing emerging anaerobes, with MALDI-TOF and 16S rRNA gene sequencing [1]. The specimen was sampled in Marseille and preserved at $-80^{\circ} \mathrm{C}$ after collection. Strain $9403502^{\mathrm{T}}$ (Table 1) was isolated in July 2009, by anaerobic cultivation on 5\% sheep blood-enriched Columbia agar (BioMerieux, Marcy l'Etoile, France). This strain exhibited a 95\% nucleotide sequence similarity with Anaerococcus prevotii [24,25]. Those similarity values are lower than the threshold recommended to delineate a new genus without carrying out DNA-DNA hybridization [38]. In the inferred phylogenetic tree, it forms a distinct lineage close to A. octavius (Figure 1). 
Table 1. Classification and general features of Anaerococcus pacaensis strain $9403502^{\top}$

\begin{tabular}{|c|c|c|c|}
\hline MIGS ID & Property & Term & Evidence code $^{\mathrm{a}}$ \\
\hline & \multirow{8}{*}{ Current classification } & Domain Bacteria & TAS [27] \\
\hline & & Phylum Firmicutes & TAS [28-30] \\
\hline & & Class Clostridia & TAS $[31,32]$ \\
\hline & & Order Clostridiales & TAS $[33,34]$ \\
\hline & & Family XI Incertae sedis & TAS [35] \\
\hline & & Genus Anaerococcus & TAS [36] \\
\hline & & Species Anaerococcus pacaensis & IDA \\
\hline & & Type strain $9403502^{\top}$ & IDA \\
\hline & Gram stain & Positive & IDA \\
\hline & Cell shape & Cocci & IDA \\
\hline & Motility & Non motile & IDA \\
\hline & Sporulation & Non spore-forming & IDA \\
\hline & Temperature range & Mesophile & IDA \\
\hline & Optimum temperature & $37^{\circ} \mathrm{C}$ & IDA \\
\hline MIGS-6.3 & Salinity & Weak growth on $\mathrm{BHI}$ medium $+1 \% \mathrm{NaCl}$ & IDA \\
\hline \multirow[t]{3}{*}{ MIGS-22 } & Oxygen requirement & Anaerobic & IDA \\
\hline & Carbon source & Unknown & NAS \\
\hline & Energy source & Unknown & NAS \\
\hline MIGS-6 & Habitat & Blood & IDA \\
\hline \multirow[t]{3}{*}{ MIGS-15 } & Biotic relationship & Free living & IDA \\
\hline & Pathogenicity & Unknown & NAS \\
\hline & Biosafety level & 2 & \\
\hline MIGS-14 & Isolation & Human blood sample & \\
\hline MIGS-4 & Geographic location & France & IDA \\
\hline MIGS-5 & Sample collection time & July 2009 & IDA \\
\hline MIGS-4.1 & Latitude & 43.296482 & IDA \\
\hline MIGS-4.1 & Longitude & 5.36978 & IDA \\
\hline MIGS-4.3 & Depth & Surface & IDA \\
\hline MIGS-4.4 & Altitude & 0 above see level & IDA \\
\hline
\end{tabular}

Evidence codes - IDA: Inferred from Direct Assay; TAS: Traceable Author Statement (i.e., a direct report exists in the literature); NAS: Non-traceable Author Statement (i.e., not directly observed for the living, isolated sample, but based on a generally accepted property for the species, or anecdotal evidence). These evidence codes are from the Gene Ontology project [37]. If the evidence is IDA, then the property was directly observed for a live isolate by one of the authors or an expert mentioned in the acknowledgements.

Different growth temperatures $\left(23^{\circ} \mathrm{C}, 25^{\circ} \mathrm{C}, 28^{\circ} \mathrm{C}\right.$, $32^{\circ} \mathrm{C}, 35^{\circ} \mathrm{C}, 37^{\circ} \mathrm{C}, 50^{\circ} \mathrm{C}$ ) were tested; no growth occurred at $23^{\circ} \mathrm{C}, 25^{\circ} \mathrm{C}, 28^{\circ} \mathrm{C}$ and $50^{\circ} \mathrm{C}$, growth occurred between $32^{\circ}$ and $37^{\circ} \mathrm{C}$, and optimal growth was observed at $37^{\circ} \mathrm{C}$.

Colonies are punctiform, very small, grey, dry and round on blood-enriched Columbia agar under anaerobic conditions using GENbag anaer (BioMérieux). Bacteria were grown on bloodenriched Columbia agar (Biomerieux), in BHI broth medium, and in Trypticase-soja TS broth medium, under anaerobic conditions using GENbag anaer (BioMérieux), under microaerophilic conditions using GENbag microaer (BioMérieux) and in the presence of air, with $5 \% \mathrm{CO}_{2}$. They also were grown under anaerobic conditions on BHI agar, and on $\mathrm{BHI}$ agar supplemented with $1 \% \mathrm{NaCl}$. Growth was achieved only anaerobically, on blood-enriched Columbia agar, and weakly on BHI agar, and BHI agar supplemented with $1 \% \mathrm{NaCl}$ after $72 \mathrm{~h}$ incubation. Gram staining showed round non spore-forming Gram-positive cocci (Figure 2). The motility test was negative. Cells grow anaerobically in TS broth medium have a mean diameter of $1.140 \mu \mathrm{m}(\mathrm{min}=$ $0.955 \mu \mathrm{m}$; $\max =1.404 \mu \mathrm{m}$ ), as determined using electron microscopic observation after negative staining (Figure 3). 


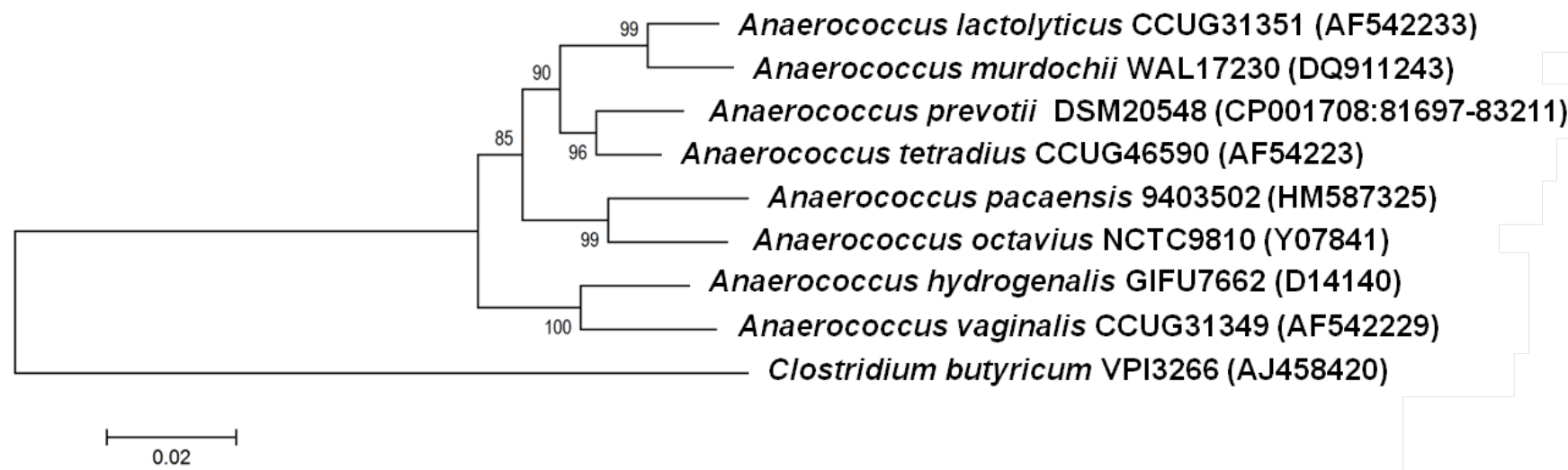

Figure 1. Phylogenetic tree highlighting the position of Anaerococcus pacaensis strain $9403502^{\top}$ relative to other type strains within the genus Anaerococcus. GenBank accession numbers are indicated in parentheses. Sequences were aligned using CLUSTALW, and phylogenetic inferences obtained using the maximum-likelihood method within the MEGA 4 software [39]. Numbers at the nodes are bootstrap values obtained by repeating the analysis 500 times the analysis to generate a majority consensus tree. Clostridium butyricum was used as outgroup. The scale bar represents a $2 \%$ nucleotide sequence divergence.

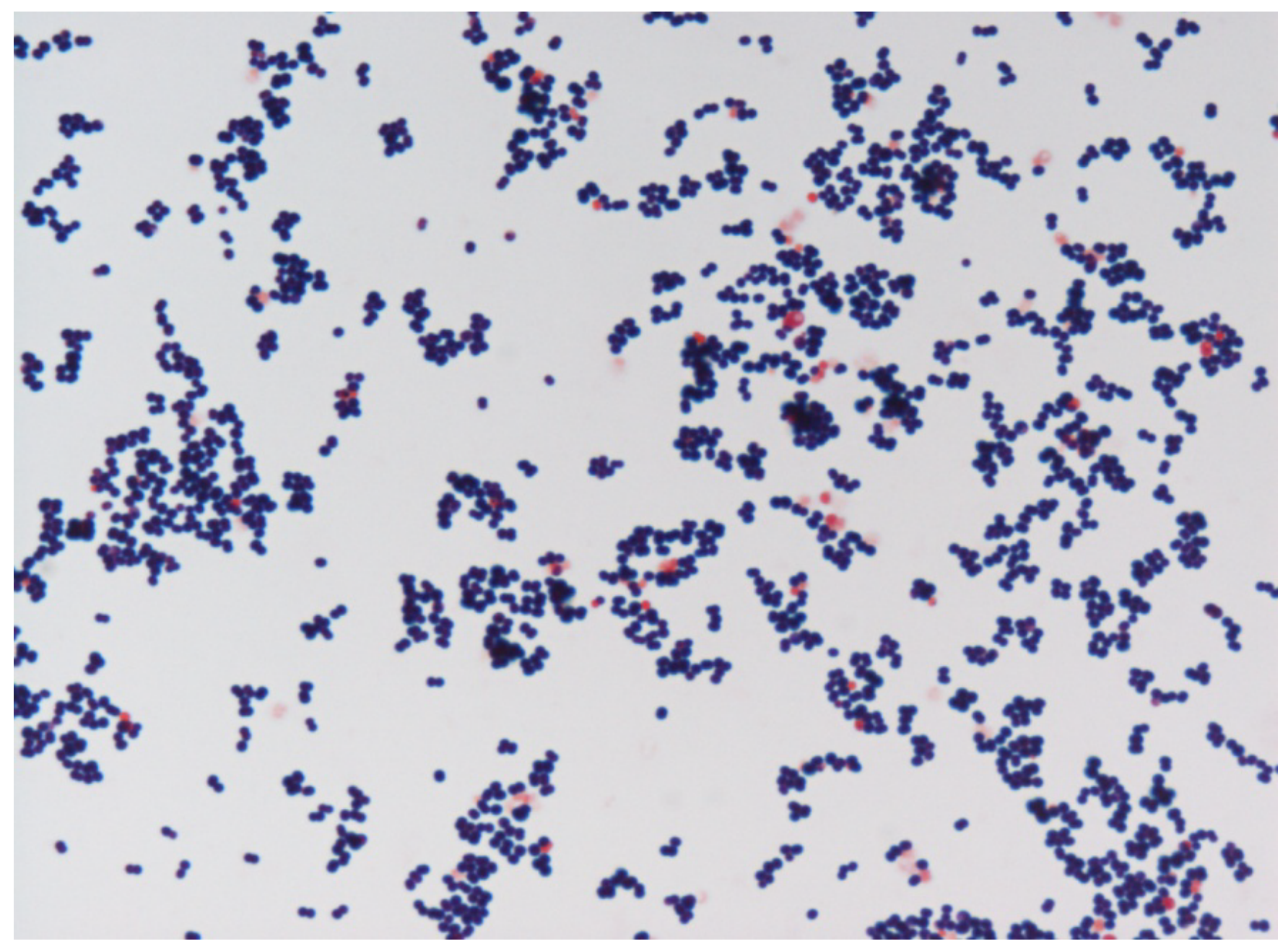

Figure 2. Gram staining of A. pacaensis strain $9403502^{\top}$ 


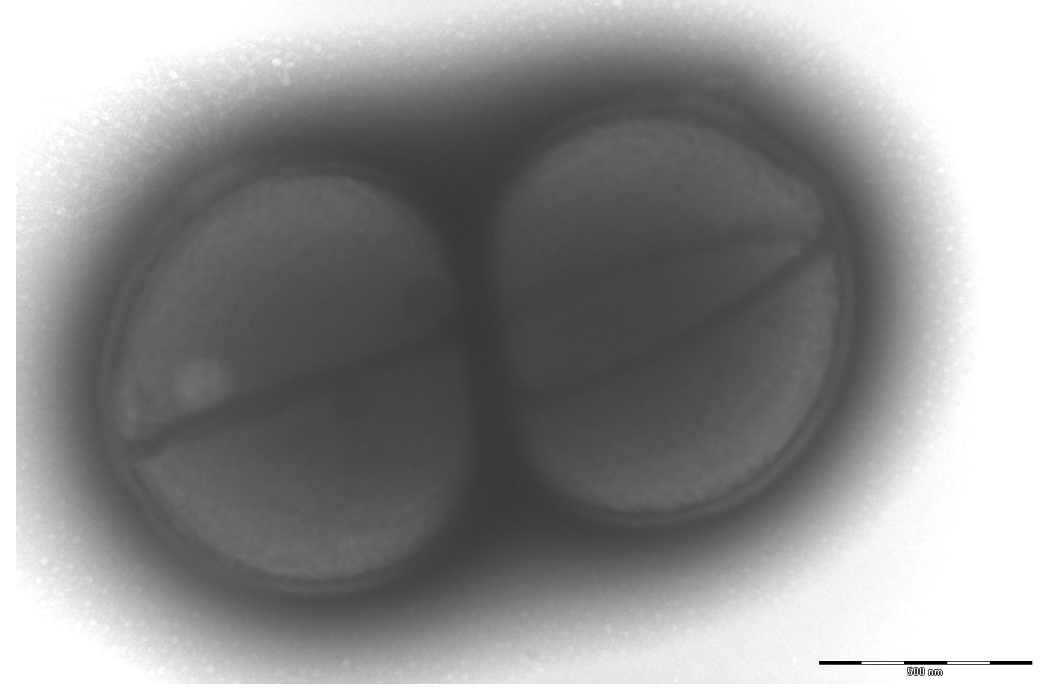

Figure 3. Transmission electron microscopy of $A$. pacaensis strain 9403502, using a Morgani 268D (Philips) at an operating voltage of $60 \mathrm{kV}$. The scale bar represents $500 \mathrm{~nm}$.

Strain $9403502^{\mathrm{T}}$ exhibited catalase activity but no oxidase activities. Using API 20A, a positive reaction could be observed only weekly for Gelatinase. Using Api Zym, a positive reaction was observed for alkaline phosphatase $(5 \mathrm{nmol}$ of hydrolyzed substrata), acid phosphatase (5nmol), naphtolphosphohydrolase $(5 \mathrm{nmol}), \quad$ and hyaluronidase (40nmol). Using Api rapid id 32A, a positive reaction could be observed only for beta glucuronydase and pyroglutamic acid arylamidase. Regarding antibiotic susceptibility, $A$. pacaensis was susceptible to penicillin $\mathrm{G}$, amoxicillin, cefotetan, imipenem, metronidazole and vancomycin. When compared to the representative species within the genus Anaerococcus, $A$. pacaensis exhibits the phenotypic characteristics details in Table 2 [40].

Matrix-assisted laser-desorption/ionization timeof-flight (MALDI-TOF) MS protein analysis was carried out as previously described [41]. A pipette tip was used to pick one isolated bacterial colony from a culture agar plate, and to spread it as a thin film on a MTP 384 MALDI-TOF target plate (Bruker Daltonics, Germany). Ten distinct deposits were done for strain $9403502^{\mathrm{T}}$ from ten isolated colonies. Each smear was overlaid with $2 \mu \mathrm{L}$ of matrix solution (saturated solution of alphacyano-4-hydroxycinnamic acid) in 50\% acetonitrile, $2.5 \%$ tri-fluoracetic acid, and allowed to dry for five minutes. Measurements were performed with a Microflex spectrometer (Bruker). Spectra were recorded in the positive linear mode for the mass range of 2,000 to 20,000 Da (parameter settings: ion source 1 (ISI), 20kV; IS2, $18.5 \mathrm{kV}$; lens, 7 $\mathrm{kV}$ ). A spectrum was obtained after 675 shots at a variable laser power. The time of acquisition was between 30 seconds and 1 minute per spot. The ten $9403502^{\mathrm{T}}$ spectra were imported into the MALDI Bio Typer software (version 2.0, Bruker) and analyzed by standard pattern matching (with default parameter settings) against the main spectra of 5,697 bacteria, in the Bio Typer database. The method of identification includes the $\mathrm{m} / \mathrm{z}$ from 3,000 to 15,000 Da. For every spectrum, 100 peaks at most were taken into account and compared with the spectra in database. A score enabled the identification, or not, from the tested species: a score $\geq 2$ with a validated species enabled the identification at the species level; a score $\geq 1.7$ but $<2$ enabled the identification at the genus level; and a score $<1.7$ did not enable any identification. For strain $9403502^{\mathrm{T}}$, the best obtained score was 1.265 , which is not significant, suggesting that our isolate was not a member of a known genus. Our database was incremented with the reference spectrum from strain $9403502^{\mathrm{T}}$ (Figure 4). A dendrogram was constructed with the MALDI Bio Typer software (version 2.0, Bruker), comparing the reference spectrum of strain $9403502^{\mathrm{T}}$ with reference spectra of 26 bacterial species, all belonging to the order of Clostridiales. In this dendrogram, strain $9403502^{\mathrm{T}}$ appears as a separated branch within the genus Anaerococcus (Figure 5). 
Table2. Differential characteristics of Anaerococcus pacaensis sp. nov., strain $9403502^{\top}$, A. octavius strain NCTC $9810^{\top}$, and A. tetradius strain DSM 2951 ${ }^{\top}$.

Properties
Cell diameter $(\mu \mathrm{m})$
Oxygen requirement
Gram stain
Optimal growth temperature

A. pacaensis

$0.9-1.4$

Anaerobic

Positive

$37^{\circ} \mathrm{C}$

Human

Habitat

\section{Enzyme production}

Indole

Alkaline Phosphatase

Urease

Catalase

Gelatinase

\section{Activity of}

Phosphatase

Acid phosphatase

Naphtolphosphohydrolase

Saccharolytic enzyme

Proteolytic enzyme

\section{Utilization of}

Glucose

Mannose

Lactose

Raffinose
Hyaluronidase
A. octavius

A. tetradius

0.7-0.9

$0.5-1.8$

Anaerobic

Anaerobic

Positive

Positive

na

na

Human

Human

na

na

na

na $\alpha$-glucosidase

$\beta$-glucosidase

$\beta$ glucuronidase
$-$

Proline arylamidase

Pyroglutamyl arylamidase
Arginine arylamidase

Histidine arylamidase 


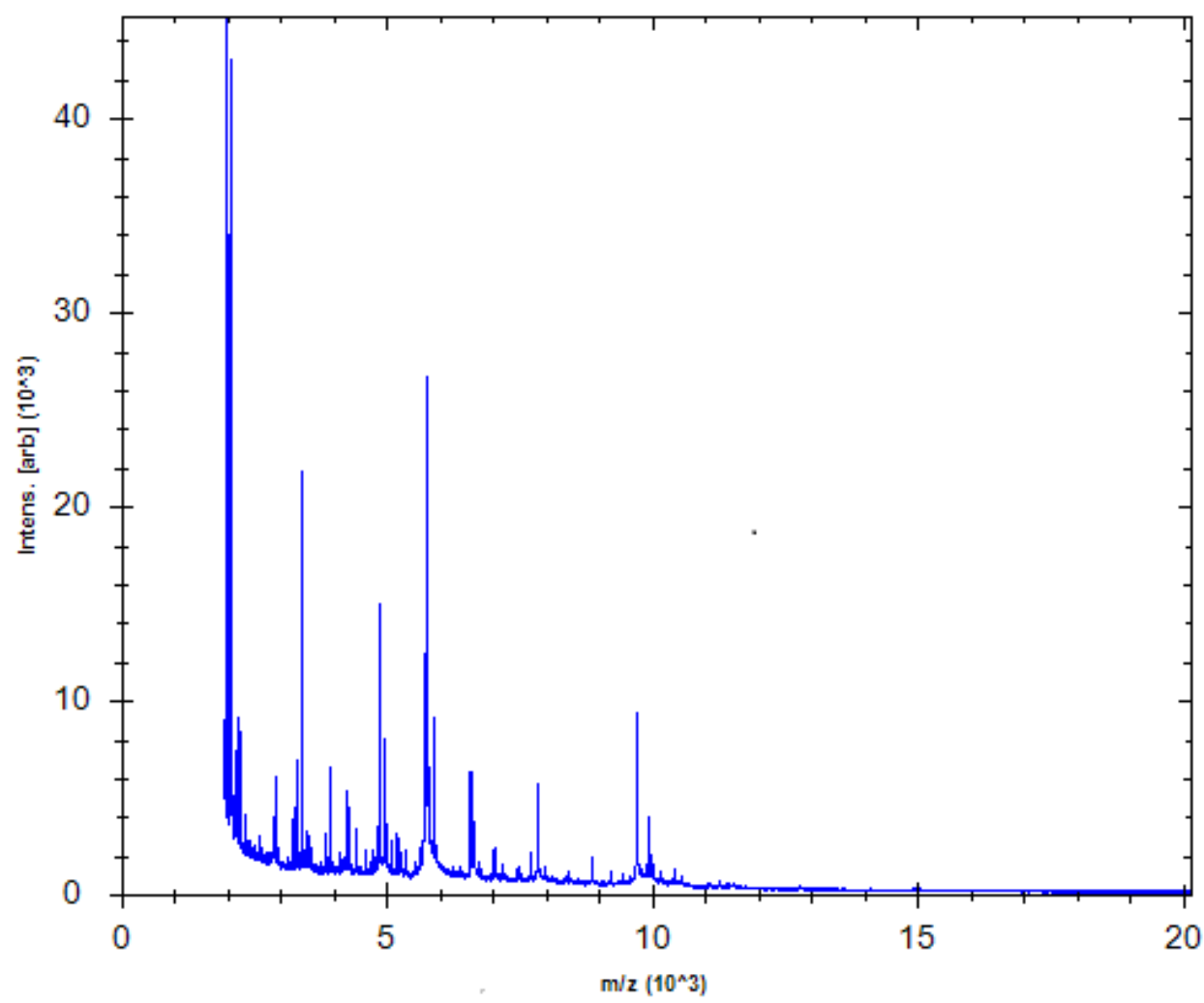

Figure 4. Reference mass spectrum from $A$. pacaensis strain 9403502. Spectra from 10 individual colonies were compared and a reference spectrum was generated.

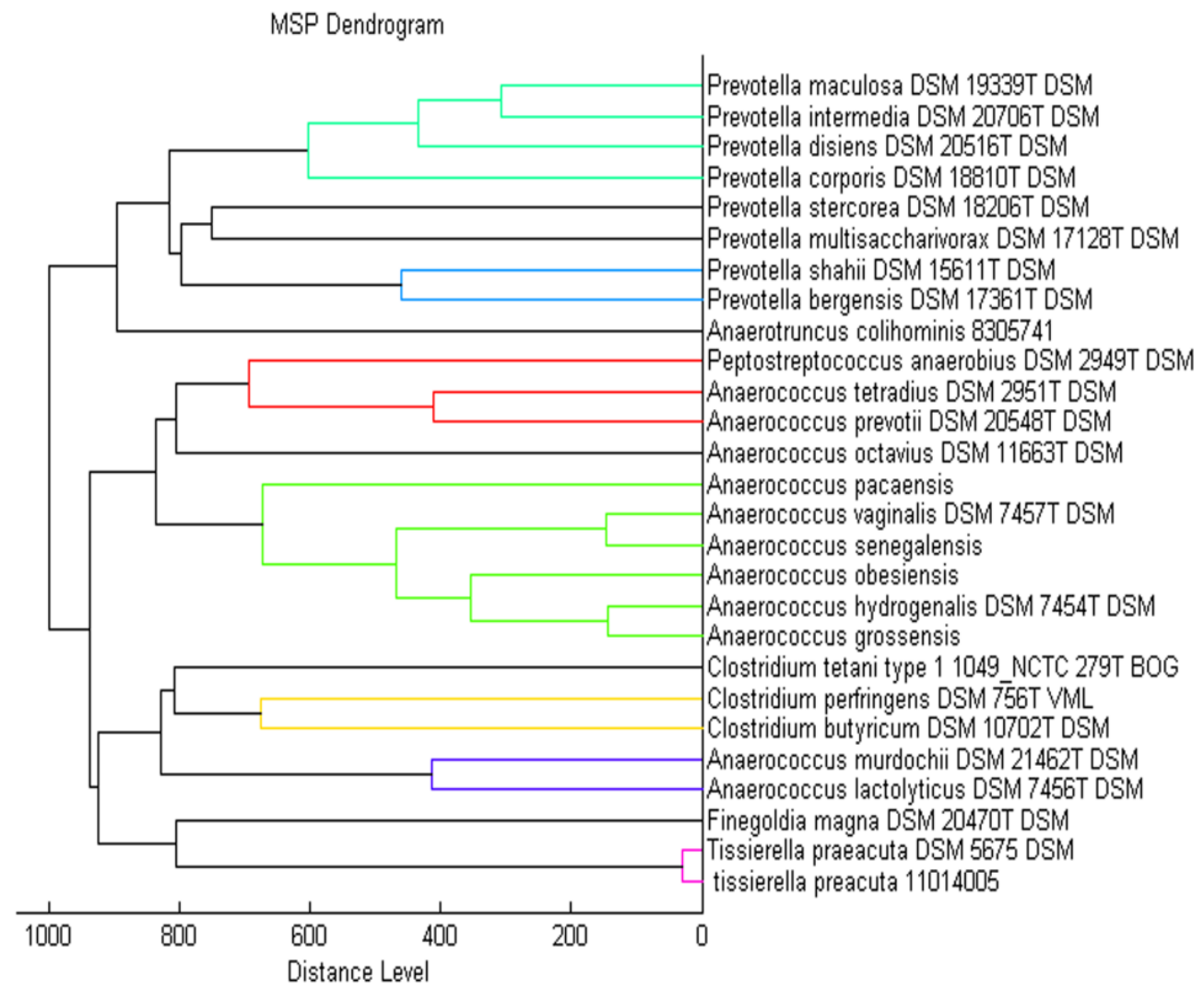

Figure 5. Dendrogram based on the comparison of the A. pacaensis strain 9403502 MALDITOF reference spectrum, and 26 other species of the order of Clostridiales. 


\section{Genome sequencing and annotation Genome project history}

The organism was selected for sequencing on the basis of its phylogenetic position, 16S rRNA similarity to other members of the Anaerococcus genus, and is part of a study prospecting anaerobic bacteria in several clinical deep samples. It was the first genome of the new genus Anaerococcus pacaensis sp. nov., and the 7th genome of Anaerococcus sp.

The Genbank accession number is CAJJ020000000 (CAJJ020000001-CAJJ020000053) and consists of 14 scaffolds with a total of 53 contigs. Table 2 shows the project information and its association with MIGS version 2.0 compliance.

\section{Growth conditions and DNA isolation}

A. pacaensis sp. nov. strain $9403502^{\mathrm{T}}$, CSUR $=\mathrm{P} 122$, $\mathrm{DSM}=26346$, was grown on blood agar medium at $37^{\circ} \mathrm{C}$ under anaerobic conditions. Eight petri dishes were spread and resuspended in $5 \times 100 \mu$ of G2 buffer. A first mechanical lysis was performed by glass powder on the Fastprep-24 device (Sample Preparation system) from MP Biomedicals, USA during $2 \times 20$ seconds. DNA was then incubated for a lysozyme treatment $\left(30\right.$ minutes at $\left.37^{\circ} \mathrm{C}\right)$ and extracted through the BioRobot EZ 1 Advanced XL (Qiagen). The DNA was then concentrated and purified on a Qiamp kit (Qiagen). The yield and the concentration were measured by the Quant-it Picogreen kit (Invitrogen) on the Genios_Tecan fluorometer at $15.7 \mathrm{ng} / \mu \mathrm{l}$.

\section{Genome sequencing and assembly}

A $3 \mathrm{~kb}$ paired end libraries was pyrosequenced on the 454 Roche Titanium. This project was loaded on a 1/4 region on PTP Picotiterplates. $5 \mu \mathrm{g}$ of DNA was mechanically fragmented on the Hydroshear device (Digilab, Holliston, MA,USA) with an enrichment size at $3-4 \mathrm{~kb}$. The DNA fragmentation was visualized through the Agilent 2100 BioAnalyzer on a DNA labchip 7,500 with an optimal size of $3.2 \mathrm{~kb}$. The library was constructed according to the 454 Titanium paired end protocol and manufacturer. Circularization and nebulization were performed and generated a pattern with an optimal at $604 \mathrm{bp}$. After PCR amplification through 15 cycles followed by double size selection, the single stranded paired end library was then quantified on the Agilent 2100 BioAnalyzer on a RNA pico 6,000 labchip at $91 \mathrm{pg} / \mu \mathrm{L}$. The library concentration equivalence was calculated at $2.76 \mathrm{E}+08$ molecules $/ \mu \mathrm{L}$. The library was stocked at $-20^{\circ} \mathrm{C}$ until using.

The library was clonal amplified with 0.5 and $1 \mathrm{cpb}$ in 2 emPCR reactions in each condition with the GS Titanium SV emPCR Kit (Lib-L) v2. The yield of the emPCR was 10.46 and $11.53 \%$ respectively according to the quality expected by the range of 5 to $20 \%$ from the Roche procedure. 790,000 beads were loaded on the GS Titanium PicoTiterPlates PTP Kit 70x75 sequenced with the GS Titanium Sequencing Kit XLR70.

The run was performed in overnight and then analyzed on the cluster through the gsRunBrowser and gsAssembler_Roche. The global 221,117 passed filter sequences generated $71.95 \mathrm{Mb}$ with a length average of $325 \mathrm{bp}$.

The 454 sequencing generated 607,067 reads (105,03 Mb) assembled into contigs and scaffolds using Newbler version 2.7 (Roche) and Opera software v1.2 [42] combined to GapFiller V1.10 [43]. Finally, the available genome consists of 14 scaffolds and 53 contigs, with a coverage of 44.9 .

Table 3. Project information

\begin{tabular}{lll}
\hline MIGS ID & Property & Term \\
\hline MIGS-31 & Finishing quality & Non-contiguous finished \\
MIGS-28 & Libraries used & One 454 PE 3-kb library \\
MIGS-29 & Sequencing platforms & 454 GS FLX+ Titanium \\
MIGS-31.2 & Sequencing coverage & 44.9 \\
MIGS-30 & Assemblers & Newbler 2.7 \\
MIGS-32 & Gene calling method & Prodigal 2.5 \\
& Genbank ID & CAJJ020000000 (CAJJ020000001-CAJJ020000053) \\
& Genbank Date of Release & April 21, 2013 \\
MIGS-13 & Source material identifier & DSM 26346 \\
& Project relevance & Prospection of anaerobic isolates in clinical samples \\
\hline
\end{tabular}




\section{Genome annotation}

Non-coding genes and miscellaneous features were predicted using RNAmmer [44], ARAGORN [45], Rfam [46], PFAM [47]. Open Reading Frames (ORFs) were predicted using Prodigal [48] with default parameters but the predicted ORFs were excluded if they were spanning a sequencing GAP region. The functional annotation was achieved using BLASTP [49] against the GenBank database [50] and the Clusters of Orthologous Groups (COG) database [51,52].

\section{Genome properties}

The genome of Anaerococcus pacaensis strain $9403502^{\mathrm{T}}$ is estimated at $2.36 \mathrm{Mb}$ long with a $\mathrm{G}+\mathrm{C}$ content of 35.05\% (Figure 6 and Table 3). A total of 2,186 protein-coding and 72 RNA genes, including
3 rRNA genes, 42 tRNA, 1 tmRNA and 26 miscellaneous other RNA were founded. The majority of the protein-coding genes were assigned a putative function $(74.1 \%)$ while the remaining ones were annotated as hypothetical proteins. The properties and the statistics of the genome are summarized in Tables 3 and 4 . The Table 5 presents the difference of gene number (in percentage) related to each COG categories between Anaerococcus pacaensis and Anaerococcus prevotii DSM 20548. The proportion of COG is highly similar between the two species. The maximum difference is related to the COG "Carbohydrate Metabolism and transportation" which does not exceed 1.94\%. The distribution of genes into COGs functional categories is presented in Table 6.

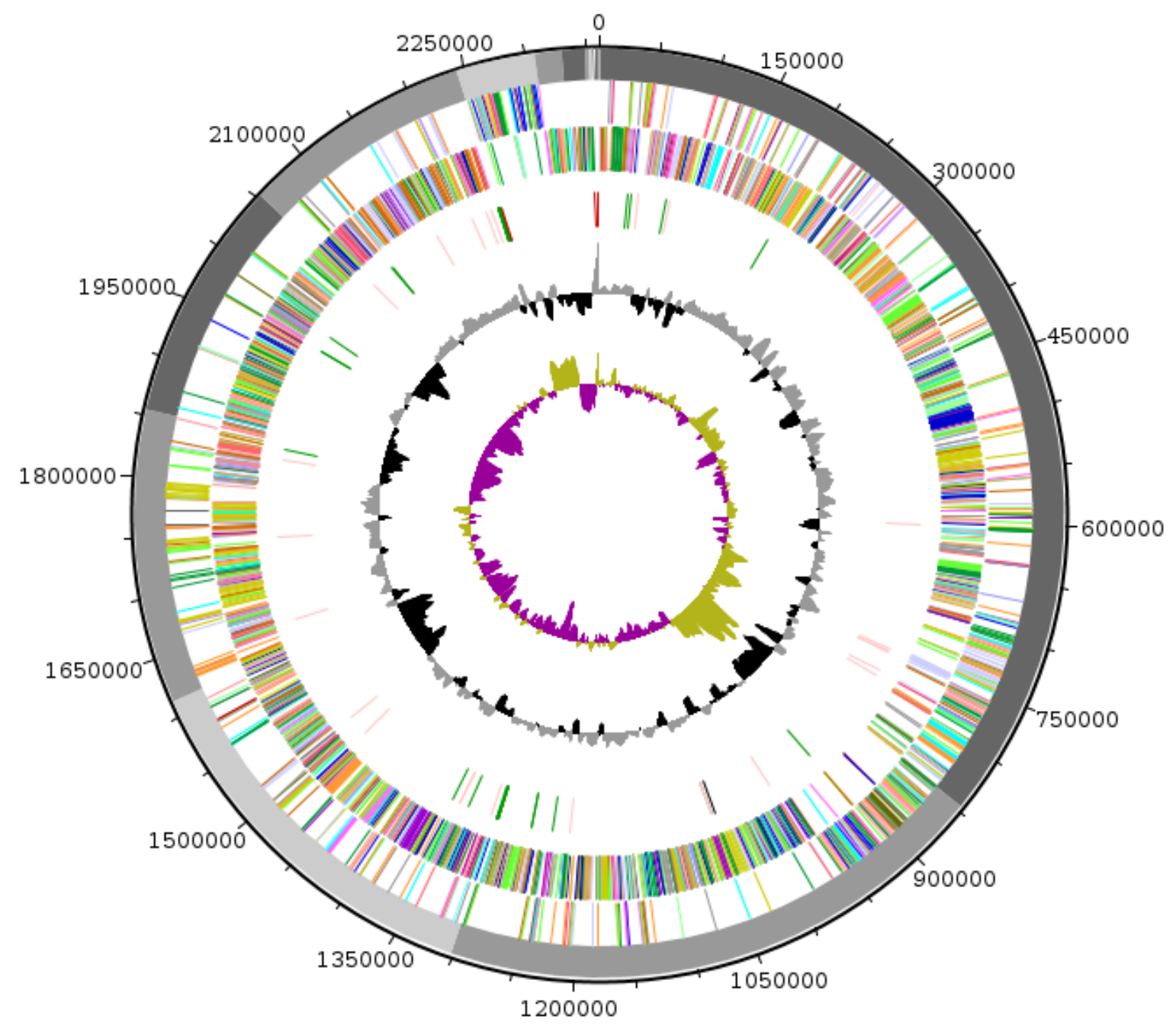

Figure 6. Graphical circular map of the genome. From outside to the center: scaffolds are in grey (unordered), genes on forward strand (colored by COG categories), genes on reverse strand (colored by COG categories), RNA genes (tRNAs green, rRNAs red, tm RNAs black, misc_RNA pink), GC content (black/grey), and GC skew (purple/olive). 
Table 4. Nucleotide content and gene count levels of the genome

\begin{tabular}{lrr}
\hline Attribute & Value & \% of Total \\
\hline Genome size (bp) & $2,360,033$ & 100 \\
DNA coding region (bp) & $2,075,031$ & 98.86 \\
DNA G+C content (bp) & 827,191 & 35.05 \\
Total genes & 2,272 & 100 \\
rRNA & 3 & 0.13 \\
tRNA & 42 & 1.85 \\
tmRNA & 1 & 0.04 \\
miscRNA & 26 & 1.14 \\
Protein-coding genes & 2,186 & 96.21 \\
Genes with function prediction & 1,620 & 74.10 \\
Genes assigned to COGs & 2,154 & 98.54 \\
\hline
\end{tabular}

*The total is based on either the size of the genome in base pairs or the total number of protein coding genes in the annotated genome

Table 5. Number of genes associated with the 25 general COG functional categories

\begin{tabular}{crrl}
\hline Code & Value & \% $^{\text {of total }}$ $^{\text {a }}$ & Description \\
\hline J & 158 & 6.91 & Translation \\
A & 4 & 0.17 & RNA processing and modification \\
K & 160 & 6.99 & Transcription \\
L & 167 & 7.3 & Replication, recombination and repair \\
B & 4 & 0.17 & Chromatin structure and dynamics \\
D & 46 & 2.01 & Cell cycle control, mitosis and meiosis \\
Y & 0 & 0 & Nuclear structure \\
V & 97 & 4.24 & Defense mechanisms \\
T & 72 & 3.15 & Signal transduction mechanisms \\
M & 93 & 4.06 & Cell wall/membrane biogenesis \\
N & 16 & 0.7 & Cell motility \\
Z & 3 & 0.13 & Cytoskeleton \\
W & 0 & 0 & Extracellular structures \\
U & 48 & 2.1 & Intracellular trafficking and secretion \\
O & 93 & 4.06 & Posttranslational modification, protein turnover, chaperones \\
C & 129 & 5.64 & Energy production and conversion \\
G & 148 & 6.47 & Carbohydrate transport and metabolism \\
E & 145 & 6.34 & Amino acid transport and metabolism \\
F & 70 & 3.06 & Nucleotide transport and metabolism \\
H & 76 & 3.32 & Coenzyme transport and metabolism \\
I & 54 & 2.36 & Lipid transport and metabolism \\
P & 157 & 6.86 & Inorganic ion transport and metabolism \\
Q & 23 & 1.01 & Secondary metabolites biosynthesis, transport and catabolism \\
R & 272 & 11.89 & General function prediction only \\
S & 253 & 11.06 & Function unknown \\
- & 32 & 1.4 & Not in COGs \\
\hline
\end{tabular}

${ }^{a}$ The total is based on the total number of protein coding genes in the annotated genome. 


\section{Insights into the genome sequence}

We made some brief comparisons against Anaerococcus prevotii DSM 20548 (NC_013171), which is currently the closest available genome. This genome contains 1 chromosome (accession number: NC_013171) and 1 plasmid (accession number: NC_013164).

The draft genome sequence of Anaerococcus pacaensis has a bigger size compared to the
Anaerococcus prevotii (respectively 2,36 Mbp and $1,99 \mathrm{Mbp}$ ). The $\mathrm{G}+\mathrm{C}$ content is slightly larger than Anaerococcus prevotii too (respectively $37.5 \%$ and $35.05 \%)$. Anaerococcus pacaensis shares more genes (2,272 genes against 1,916 genes), however the ratios of genes per $\mathrm{Mb}$ is very similar $(962,71-$ 962,81).

Table 6. Percentage of genes associated with the 25 general COG functional categories for Anaerococcus pacaensis and Anaerococcus prevotii DSM 20548.

\begin{tabular}{|c|c|c|c|c|}
\hline Code & COG description & A. pacaensis \%age & A. prevotii \%age & Difference (in \%) \\
\hline J & Translation & 6.91 & 7.53 & -0.62 \\
\hline A & RNA processing and modification & 0.17 & 0.10 & 0.07 \\
\hline K & Transcription & 6.99 & 6.91 & 0.08 \\
\hline L & Replication, recombination and repair & 7.30 & 6.13 & 1.17 \\
\hline B & Chromatin structure and dynamics & 0.17 & 0.16 & 0.01 \\
\hline D & Cell cycle control, mitosis and meiosis & 2.01 & 1.56 & 0.45 \\
\hline Y & Nuclear structure & 0.00 & 0.05 & -0.05 \\
\hline V & Defense mechanisms & 4.24 & 3.43 & 0.81 \\
\hline $\mathrm{T}$ & Signal transduction mechanisms & 3.15 & 3.17 & -0.02 \\
\hline M & Cell wall/membrane biogenesis & 4.06 & 5.24 & -1.18 \\
\hline $\mathrm{N}$ & Cell motility & 0.70 & 0.36 & 0.34 \\
\hline Z & Cytoskeleton & 0.13 & 0.16 & -0.03 \\
\hline W & Extracellular structures & 0.00 & 0.00 & 0.00 \\
\hline$U$ & Intracellular trafficking and secretion & 2.10 & 1.92 & 0.18 \\
\hline $\mathrm{O}$ & $\begin{array}{l}\text { Posttranslational modification, protein turnover, } \\
\text { chaperones }\end{array}$ & 4.06 & 3.63 & 0.43 \\
\hline $\mathrm{C}$ & Energy production and conversion & 5.64 & 6.59 & -0.95 \\
\hline G & Carbohydrate transport and metabolism & 6.47 & 8.41 & -1.94 \\
\hline $\mathrm{E}$ & Amino acid transport and metabolism & 6.34 & 6.65 & -0.31 \\
\hline $\mathrm{F}$ & Nucleotide transport and metabolism & 3.06 & 3.69 & -0.63 \\
\hline $\mathrm{H}$ & Coenzyme transport and metabolism & 3.32 & 3.58 & -0.26 \\
\hline I & Lipid transport and metabolism & 2.36 & 2.34 & 0.02 \\
\hline$P$ & Inorganic ion transport and metabolism & 6.86 & 6.80 & 0.06 \\
\hline Q & $\begin{array}{l}\text { Secondary metabolites biosynthesis, transport and } \\
\text { catabolism }\end{array}$ & 1.01 & 0.78 & 0.23 \\
\hline $\mathrm{R}$ & General function prediction only & 11.89 & 11.21 & 0.68 \\
\hline$S$ & Function unknown & 11.06 & 9.61 & 1.45 \\
\hline- & Not in COGs & 1.40 & 0.99 & 0.41 \\
\hline
\end{tabular}

\section{Conclusion}

On the basis of phenotypic, phylogenetic and genomic analysis, we formally propose the creation of Anaerococcus pacaensis, whichcontains the strain $9403502^{\mathrm{T}}$. This bacterium has been found in Marseille, France.

Description of Anaerococcus pacaensis sp. nov. Anaerococcus pacaensis (pa.ca'en.sis L. gen. masc. n. pacaensis, of PACA, the acronym of Provence
Alpes Côte d'Azur, the region where was isolated Anaerococcus pacaensis). Isolated from a blood sample from a patient from Marseille. A. pacaensis is a Gram-positive cocci, obligate anaerobic, nonspore-forming bacterium. Grows on axenic medium at $37^{\circ} \mathrm{C}$ in anaerobic atmosphere. Negative for indole. Non-motile. The $\mathrm{G}+\mathrm{C}$ content of the genome is $35.05 \%$. The type strain is $9403502^{\mathrm{T}}(=$ CSUR P122 = DSM 26346). 


\section{References}

1. La Scola B, Fournier PE, Raoult D. Burden of emerging anaerobes in the MALDI-TOF and $16 \mathrm{~S}$ rRNA gene sequencing era. Anaerobe 2011; 17:106-112. PubMed http://dx.doi.org/10.1016/j.anaerobe.2011.05.010

2. Rossello-Mora R. DNA-DNA Reassociation Methods Applied to Microbial Taxonomy and Their Critical Evaluation. In: Stackebrandt E (ed), Molecular Identification, Systematics, and population Structure of Prokaryotes. Springer, Berlin, 2006, p. 23-50.

3. Stackebrandt E, Ebers J. Taxonomic parameters revisited: tarnished gold standards. Microbiol Today 2006; 33:152-155.

4. Welker M, Moore ER. Applications of whole-cell matrix-assisted laser-desorption/ionization timeof-flight mass spectrometry in systematic microbiology. Syst Appl Microbiol 2011; 34:2-11. PubMed

http://dx.doi.org/10.1016/j.syapm.2010.11.013

5. Tindall BJ, Rosselló-Móra R, Busse HJ, Ludwig W, Kämpfer P. Notes on the characterization of prokaryote strains for taxonomic purposes. Int I Syst Evol Microbiol 2010; 60:249-266. PubMed http://dx.doi.org/10.1099/ijs.0.016949-0

6. Kokcha S, Michra AK, Lagier JC, Million M, Leroy Q, Raoult D, Fournier PE. Non-contiguousfinished genome sequence and description of $\mathrm{Ba}-$ cillus timonensis sp. nov. Stand Genomic Sci 2012; 6:346-355. PubMed http://dx.doi.org/10.4056/sigs.2776064

7. Lagier JC, El Karkouri K, Nguyen TT, Armougom $F$, Raoult D, Fournier PE. Non-contiguousfinished genome sequence and description of Anaerococcus senegalensis sp. nov. Stand Genomic Sci 2012; 6:116-125. PubMed http://dx.doi.org/10.4056/sigs.2415480

8. Mishra AK, Gimenez G, Lagier JC, Robert C, Raoult D, Fournier PE. Non-contiguous-finished genome sequence and description of Alistipes senegalensis sp. nov. Stand Genomic Sci 2012; 6:304-314. http://dx.doi.org/10.4056/sigs.2625821

9. Lagier JC, Armougom F, Mishra AK, Nguyen TT, Raoult D, Fournier PE. Non-contiguous-finished genome sequence and description of Alistipes timonensis sp. nov. Stand Genomic Sci 2012; 6:315-324. PubMed

10. Mishra AK, Lagier JC, Robert C, Raoult D, Fournier PE. Non-contiguous-finished genome se- quence and description of Clostridium senegalenses sp. nov. Stand Genomic Sci 2012; 6:386-395. PubMed

11. Mishra AK, Lagier JC, Robert C, Raoult D, Fournier PE. Non-contiguous-finished genome sequence and description of Peptinophilus timonensis sp. nov. Stand Genomic Sci 2012; 7:111. PubMed http://dx.doi.org/10.4056/sigs.2956294

12. Mishra AK, Lagier JC, Rivet R, Raoult D, Fournier $P E$. Non-contiguous finished genome sequence and description of Paenibacillus senegalensis sp. nov. Stand Genomic Sci 2012; 7:70-81. PubMed

13. Lagier JC, Gimenez G, Robert C, Raoult D, Fournier PE. Non-contiguous finished genome sequence and description of Herbaspirillum massiliense sp. nov. Stand Genomic Sci 2012; 7:200-209. PubMed

14. Roux V, El Karkouri K, Lagier JC, Robert C, Raoult $D$. Non-contiguous finished genome sequence and description of Kurthia massiliensis sp. nov. Stand Genomic Sci 2012; 7:221-232. PubMed http://dx.doi.org/10.4056/sigs.3206554

15. Kokcha S, Ramasamy D, Lagier JC, Robert C, Raoult D, Fournier PE. Non-contiguous finished genome sequence and description of Brevibacterium senegalense sp. nov. Stand Genomic Sci 2012; 7:233-245. PubMed http://dx.doi.org/10.4056/sigs.3256677

16. Ramasamy D, Kokcha S, Lagier JC, N'Guyen TT, Raoult D, Fournier PE. Non-contiguous finished genome sequence and description of Aeromicrobium massilense sp. nov. Stand Genomic Sci 2012; 7:246-257. PubMed http://dx.doi.org/10.4056/sigs.3306717

17. Lagier JC, Ramasamy D, Rivet R, Raoult D, Fournier PE. Non-contiguous finished genome sequence and description of Cellulomonas massiliensis sp. nov. Stand Genomic Sci 2012; 7:258-270. PubMed http://dx.doi.org/10.4056/sigs.3316719

18. Lagier JC, El Karkouri K, Rivet R, Couderc C, Raoult D, Fournier PE. Non-contiguous finished genome sequence and description of Senegalemassilia anaerobia sp. nov. Stand Genomic Sci 2013; 7:343-356. http://dx.doi.org/10.4056/sigs.3246665

19. Mishra AK, Hugon P, Lagier JC, Nguyen TT, Robert C, Couderc C, Raoult D, Fournier PE. Noncontiguous finished genome sequence and de- 
scription of Peptoniphilus obesi sp. nov. Stand

Genomic Sci 2013; 7:357-369.

http://dx.doi.org/10.4056/sigs.32766871

20. Mishra AK, Lagier JC, Nguyen TT, Raoult D, Fournier PE. Non-contiguous finished genome sequence and description of Peptoniphilus senegalensis sp. nov. Stand Genomic Sci 2013; 7:370-381. http://dx.doi.org/10.4056/sigs.3366764

21. Lagier JC, El Karkouri K, Mishra AK, Robert C, Raoult D, Fournier PE. Non-contiguous finished genome sequence and description of Enterobacter massiliensis sp. nov. Stand Genomic Sci 2013; 7:399-412. http://dx.doi.org/10.4056/sigs.3396830

22. Hugon P, Ramasamy D, Lagier JC, Rivet R, Couderc C, Raoult D, Fournier PE. Noncontiguous finished genome sequence and description of Alistipes obesi sp. nov. Stand Genomic Sci 2013; 7:427-439. http://dx.doi.org/10.4056/sigs.3336746

23. Mishra AK, Hugon P, Robert C, Couderc C, Raoult D, Fournier PE. Non-contiguous finished genome sequence and description of Peptoniphilus grossensis sp. nov. Stand Genomic Sci 2012; 7:320-330. PubMed

24. Ezaki T, Kawamura Y, Li N, Li ZY, Zhao L, Shu S. Proposal of the genera Anaerococcus gen. nov., Peptoniphilus gen. nov. and Gallicola gen. nov. for members of the genus Peptostreptococcus. Int J Syst Evol Microbiol 2001; 51:1521-1528. PubMed

25. Foubert EL, Douglas HC. Studies on the Anaerobic Micrococci: I. Taxonomic Considerations. J Bacteriol 1948; 56:25-34.

26. Murdoch DA, Collins MD, Willems A, Hardie JM, Young KA, Magee JT. Description of three new species of the genus Peptostreptococcus from human clinical specimens: Peptostreptococcus harei sp. nov., Peptostreptococcus ivorii sp. nov., and Peptostreptococcus octavius sp. nov. Int J Syst Bacteriol 1997; 47:781-787. http://dx.doi.org/10.1099/00207713-47-3-781

27. Woese CR, Kandler O, Wheelis ML. Towards a natural system of organisms: proposal for the domains Archae, Bacteria, and Eukarya. Proc Natl Acad Sci USA 1990; 87:4576-4579. PubMed http://dx.doi.org/10.1073/pnas.87.12.4576

28. Gibbons NE, Murray RGE. Proposals Concerning the Higher Taxa of Bacteria. Int I Syst Bacteriol 1978; 28:1-6. http://dx.doi.org/10.1099/00207713-28-1-1
29. Garrity GM, Holt JG. The Road Map to the Manual. In: Garrity GM, Boone DR, Castenholz RW (eds), Bergey's Manual of Systematic Bacteriology, Second Edition, Volume 1, Springer, New York, 2001, p. 119-169.

30. Murray RGE. The Higher Taxa, or, a Place for Everything...? In: Holt JG (ed), Bergey's Manual of Systematic Bacteriology, First Edition, Volume 1, The Williams and Wilkins Co., Baltimore, 1984, p. 31-34.

31. List of new names and new combinations previously effectively, but not validly, published. List no. 132. Int / Syst Evol Microbiol 2010; 60:469472. http://dx.doi.org/10.1099/ijs.0.022855-0

32. Rainey FA. Class II. Clostridia class nov. In: De Vos P, Garrity G, Jones D, Krieg NR, Ludwig W, Rainey FA, Schleifer KH, Whitman WB (eds), Bergey's Manual of Systematic Bacteriology, Second Edition, Volume 3, Springer-Verlag, New York, 2009, p. 736.

33. Skerman VBD, Sneath PHA. Approved list of bacterial names. Int J Syst Bact 1980; 30:225-420. http://dx.doi.org/10.1099/00207713-30-1-225

34. Prevot AR. Dictionnaire des bactéries pathogens. In: Hauduroy P, Ehringer G, Guillot G, Magrou J, Prevot AR, Rosset, Urbain A (eds). Paris, Masson, 1953, p.1-692.

35. Ludwig W, Schleifer KH, Whitman WB. Revised road map to the phylum Firmicutes. In: Bergey's Manual of Systematic Bacteriology, 2nd ed., vol. 3 (The Firmicutes) (P. De Vos, G. Garrity, D. Jones, N.R. Krieg, W. Ludwig, F.A. Rainey, K.-H. Schleifer, and W.B. Whitman, eds.), SpringerVerlag, New York. (2009) pp. 1-13

36. Ezaki T, Kawamura Y, Li N, Li ZY, Zhao L, Shu S. Proposal of the genera Anaerococcus gen. nov., Peptoniphilus gen. nov. and Gallicola gen. nov. for members of the genus Peptostreptococcus. Int J Syst Evol Microbiol 2001; 51:1521-1528. PubMed

37. Ashburner M, Ball CA, Blake JA, Botstein D, Butler H, Cherry JM, Davis AP, Dolinski K, Dwight SS, Eppig JT, et al. Gene ontology: tool for the unification of biology. The Gene Ontology Consortium. Nat Genet 2000; 25:25-29. PubMed http://dx.doi.org/10.1038/75556

38. Schloss PD, Handelsman J. Status of the microbial census. Microbiol Mol Biol Rev 2004; 68:686691. PubMed http://dx.doi.org/10.1128/MMBR.68.4.686691.2004 
39. Tamura K, Dudley J, Nei M, Kumar S. MEGA4: Molecular Evolutionary Genetics Analysis (MEGA) software version 4.0. Mol Biol Evol 2007; 24:1596-1599. PubMed http://dx.doi.org/10.1093/molbev/msm092

40. Murdoch DA. Gram-positive anaerobic cocci. Clin Microbiol Rev 1998; 11:81-120. PubMed

41. Seng P, Drancourt M, Gouriet F, La Scola B, Fournier PE, Rolain JM, Raoult D. Ongoing revolution in bacteriology: routine identification of bacteria by matrix-assisted laser desorption ionization time-of-flight mass spectrometry. Clin Infect Dis 2009; 49:543-551. PubMed http://dx.doi.org/10.1086/600885

42. Gao S, Sung WK, Nagarajan N. Opera: reconstructing optimal genomic scaffolds with highthroughput paired-end sequences. J Comput Biol 2011; 18:1681-1691. PubMed http://dx.doi.org/10.1089/cmb.2011.0170

43. Boetzer M, Pirovano W. Toward almost closed genomes with GapFiller. Genome Biol 2012; 13:R56. PubMed http://dx.doi.org/10.1186/gb2012-13-6-r56

44. Lagesen K, Hallin P, Rodland EA, Staerfeldt HH, Rognes T, Ussery DW. RNAmmer: consistent and rapid annotation of ribosomal RNA genes. Nucleic Acids Res 2007; 35:3100-3108. PubMed http://dx.doi.org/10.1093/nar/gkm160

45. Laslett D, Canback B. ARAGORN, a program to detect tRNA genes and tmRNA genes in nucleotide sequences. Nucleic Acids Res 2004; 32:1116. PubMed http://dx.doi.org/10.1093/nar/gkh152
46. Griffiths-Jones S, Bateman A, Marshall M, Khanna A, Eddy SR. Rfam: an RNA family database. $\mathrm{Nu}$ cleic Acids Res 2003; 31:439-441. PubMed http://dx.doi.org/10.1093/nar/gkg006

47. Punta M, Coggill PC, Eberhardt RY, Mistry J, Tate J, Boursnell C, Pang N, Forslund K, Ceric G, Clements J, et al. The Pfam protein families database. Nucleic Acids Res 2012; 40:D290-D301. PubMed http://dx.doi.org/10.1093/nar/gkr1065

48. Hyatt D, Chen GL, Locascio PF, Land ML, Larimer FW, Hauser LJ. Prodigal: prokaryotic gene recognition and translation initiation site identification. BMC Bioinformatics 2010; 11:119. PubMed http://dx.doi.org/10.1186/1471-2105-11-119

49. Camacho C, Coulouris G, Avagyan V, Ma N, Papadopoulos J, Bealer K, Madden TL. BLAST+: architecture and applications. BMC Bioinformatics 2009; 10:421. PubMed http://dx.doi.org/10.1186/1471-2105-10-421

50. Benson DA, Karsch-Mizrachi I, Clark K, Lipman DJ, Ostell J, Sayers EW. Gen Bank. Nucleic Acids Res 2012; 40:D48-D53. PubMed http://dx.doi.org/10.1093/nar/gkr1202

51. Tatusov RL, Galperin MY, Natale DA, Koonin EV. The COG database: a tool for genomoe-scale analysis of protein functions and evolution. $\mathrm{Nu}$ cleic Acids Res 2000; 28:33-36. PubMed http://dx.doi.org/10.1093/nar/28.1.33

52. Tatusov RL, Koonin EV, Lipman DJ. A genomic perspective on protein families. Science 1997; 278:631-637. PubMed http://dx.doi.org/10.1126/science.278.5338.631 